http://dx.doi.org/10.5007/2175-7941.2012v29n2p205

A Prova Brasil e o Sistema Nacional de Avaliação da Educação Básica (SAEB) são dois exames que fornecem dados para a avaliação da qualidade do ensino oferecido pelo sistema educacional brasileiro.

A Prova Brasil, criada em 2005, avalia as habilidades em Língua Portuguesa (foco em leitura) e Matemática (foco na resolução de problemas) e é realizada apenas com estudantes do Ensino Fundamental - de $5^{\circ}$ e $9^{\circ}$ anos - de escolas públicas, localizadas em áreas urbanas e rurais. A amostra é quase universal, pois todos os estudantes das séries avaliadas, de todas as escolas públicas, devem fazer a prova, desde que a escola tenha mais de vinte alunos na série em questão. Os seus resultados podem medir o desempenho do país como um todo, por regiões, por unidades da federação, por municípios e por escolas.

O SAEB utiliza parte dos resultados da Prova Brasil. Além dos estudantes de $5^{\circ}$ e $9^{\circ}$ anos do Ensino Fundamental, também envolve estudantes do $3^{\circ}$ ano do Ensino Médio das redes pública e privada; é realizado a cada dois anos e os seus resultados contemplam o Brasil como um todo, as suas regiões e as unidades da federação. Apenas parte dos estudantes das séries avaliadas participa dessa prova, ou seja, a avaliação é feita por amostra. Seus resultados visam fornecer subsídios para a formulação, reformulação e o monitoramento de políticas na área educacional.

O Índice de Desenvolvimento da Educação Básica (IDEB), criado em 2007 pelo Instituto Nacional de Estudos e de Pesquisas Educacionais Anísio Teixeira (INEP), é um indicador da qualidade da educação, calculado com base na taxa de rendimento escolar (aprovação e evasão) e no desempenho dos alunos no SAEB e na Prova Brasil. Para o seu cálculo, são utilizados os dados sobre a aprovação escolar, obtidos no Censo Escolar, e as médias de desempenho nas avaliações do INEP - o SAEB e a Prova Brasil. É expresso em uma escala de zero a dez.

Em 2005, foram estabelecidas metas educacionais, a serem cumpridas e verificadas a cada dois anos, pelo país, pelas escolas e por municípios e unidades da Federação. A intenção era que houvesse uma evolução do IDEB de 3,8, obtido em 2005 para o Ensino Fundamental, de modo que, em 2022, ano do bicentenário da Independência, alcançasse o valor $6,0^{1}$.

\footnotetext{
${ }^{1}$ Patamar educacional da média dos países da Organização para a Cooperação e Desenvolvimento Econômico (OCDE) - organização de cooperação internacional, fundada em 1960,
} 
A tabela ${ }^{2}$ a seguir apresenta os valores do IDEB desde 2005.
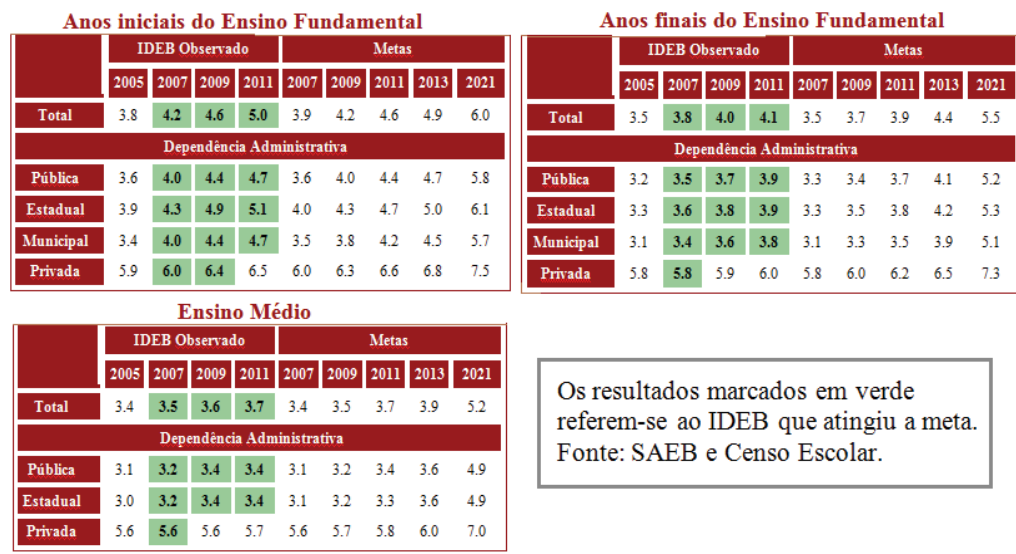

Privada

Os resultados marcados em verde referem-se ao IDEB que atingiu a meta. Fonte: SAEB e Censo Escolar.

O maior avanço no IDEB ocorreu nos anos iniciais do Ensino Fundamental, principalmente devido ao aumento das taxas de aprovação, que é um dos componentes do cálculo desse índice (resultado da multiplicação entre o indicador de fluxo e o indicador de aprendizado), já que o outro integrante, o aprendizado, avançou muito pouco. Além disso, no Ensino Médio, houve uma clara estagnação, pois cresceu apenas 0,3 pontos entre 2005 e 2011, apesar de as metas terem sido cumpridas.

O Brasil ocupa, hoje, o $88^{\circ}$ lugar no ranking da educação da Organização das Nações Unidas (ONU), e é o penúltimo no que se refere ao resultado do exame Pisa, que avalia a educação em 56 países. Claramente, isto não é compatível com um país que tem a sexta maior economia do mundo.

Segundo o senador Cristovam Buarque, "o Brasil vive um apagão intelectual", afirmando, ainda, que "avançamos ficando para trás. Coreia do Sul, Índia, China e Irlanda, que há trinta anos atrás estavam em situação pior que o Brasil, hoje estão melhores, pois fizeram o dever de casa. O nosso dever de casa é fazer com que as 300 melhores escolas do IDEB sejam transformadas em duzentas mil".

\section{Os editores}

que busca o desenvolvimento econômico permanente entre os trinta e quatro países membros.

$2<$ http://ideb.inep.gov.br/resultado/resultado/resultadoBrasil.seam?cid=419791> 